\title{
IMPORTANTE APORTE DEL INDICE DE DEGRADACIÓN DE AGREGADOS PÉTREOS (ID) SOMETIDOS A DISTINTOS TIPOS DE IMPACTOS, PARA DETERMINAR SU APTITUD VIAL EN LA ZONA DE BAHIA BLANCA (PROVINCIA DE BUENOS AIRES)
}

Ing. Silvia Alvarez - Ing. Lucrecia Romero (*).

\section{RESUMEN:}

Este artículo propone: en primera instancia una sucinta revisión de trabajos y estudios realizados durante cuarenta y cinco años - por parte de ingenieros, geólogos y técnicos de la Dirección Nacional de Vialidad y de Vialidad de la Provincia de Buenos Aires- referentes a las exigencias de las Especificaciones Estatales, en lo atinente a la durabilidad de los agregados pétreos y en particular al mismo ensayo de Desgaste con el equipo Los Angeles; y su relación con el ensayo de Fragmentación Dinámica. Y para finalizar la utilización de las granulometrías de los áridos degradados -a posteriori de los ensayos mencionados-y su relación con la degradación granulométrica luego de la compactación Marshall-como otro elemento a considerar en el control de calidad.

PALABRAS CLAVES: agregados pétreos, aptitud vial, normas, ensayos, control, desgaste, degradación.

Debido a la importancia en cuestiones de costos, de la utilización de materiales de la zona en la construcción vial, es que decidimos profundizar en el análisis de los criterios de aptitud de materiales como ya han venido planteando en distintos Congresos.

... "La idea de la ejecución de los ensayos de agregados pétreos es obtener una predicción de serviciabilidad de las obras que integran. El ensayo de desgaste Los Angeles es uno de ellos; probablemente el más difundido universalmente, pero también al que se le ha realizado una continua crítica"(REF 1) ... "No discutiremos el valor que tiene esta normalización como lenguaje comparativo casi universal, ni la sencillez de la técnica de ensayo, cuyo instrumental posibilita la determinación de un resultado al pie de obra, con relativa rapidez. Sin embargo, existen algunos factores de incertidumbre que hacen aconsejable el paulatino reemplazo de este ensayo por otros más adaptados a la realidad" (REF 2)

Hace más de cuatro décadas, se presentó a un congreso argentino un trabajo sobre la degradación de los materiales granulares en relación con su durabilidad en servicio (REF 1); los autores proponían considerar las curvas granulométricas de los áridos de-

(*) Universidad Nacional del Sur, Departamento de Ingeniería. Av. Alem 1257 (8000) Bahía Blanca. Provincia de Buenos Aires Telefax: 0291-4595157.salvarez@criba.edu.ar (cel 0291-154134747), lucrecia.romero@uns.edu.ar (cel 0291-154615609) 
gradados y compararlas con la del mismo material antes de realizarle el ensayo; de manera de establecer alguna valoración que permitiera apreciar el comportamiento de todo el material en los diferentes tamices y no solo en el No 12 como propone el ensayo de marra. Así definieron un Indice de Degradación (ID): como la diferencia entre las ordenadas de las curvas granulométricas después y antes del ensayo de desgaste Los Angeles, dividido entre la cantidad de tamices utilizados. Este recurso permitiría catalogar cada material como apto para: carpeta de rodamiento, capa de base o capas inferiores, según fuera el ID menor o mayor de ciertos valores y así se evitaría despreciarlo por completo.

E1 Dr Saumench de la DNV insistía en la necesidad de considerar otros elementos para ser más justos con los agregados pétreos, al menos en el control de la dureza y así decía ... "Aun si un agregado sobrepasara algo los limites de seguridad conocidos y exigidos para algún tipo de ensayo, pero si la capacidad potencial y las ventajas económicas de su empleo fueran favorables, pueden realizarse estudios, investigaciones y constataciones de la obra en que intervienen esos granulares dudosos. Los ensayos de constataciones podrian hacer probable el empleo de aquellos agregados cuestionados, en el caso de que cumplieran un buen comportamiento en servicio... Es siempre útil y conveniente correlacionar los resultados obtenidos en los ensayos que se efectúan para una misma clase de agregados, e interpretarlos". (REF 1)

Con estos antecedentes, el grupo ProIDI: Nuevas Tecnologías en Concretos Asfálticos -perteneciente al Departamento de Ingeniería de la Universidad Nacional del Sur de la ciudad de Bahía Blanca, Provincia de Buenos Aires, acometió la tarea de dibujar las curvas granulométricas de los áridos provenientes de canteras comerciales de la zona (granitos y cuarcitas), después de haber sido sometidos a distintos tipos de impactos. Se redactó un informe y se presentó en la XXXVI Reunión del Asfalto (REF 4), desarrollada -con motivo del Bicentenario de la Patria- en la ciudad de Buenos Aires el 2010.

Con el fin de acercar el conocimiento al desarrollo de la zona en que vivimos, es que planteamos la inquietud sobre el uso del material estudiado, a fin de ser tenido en cuenta a fines comerciales, aunque no se encuadren totalmente dentro de las normativas de las entidades viales gubernamentales.

Una vez que se calibró el Fragmentador Dinámico con los resultados del Ensayo los Angeles, se procedió al estudio de la degradación de los agregados pétreos luego de los ensayos de desgaste a través del índice de degradación (ID). Se preparó la gradación B (Granito6-20 de la zona) con $2.500 \mathrm{~g}$ de material comprendido entre los tamices de $3 / 4$ " y $1 / 2$ " (pasa $19 \mathrm{~mm}$ y retenido sobre 12,7 $\mathrm{mm}$ ) más $2.500 \mathrm{~g}$ de material comprendido entre $1 / 2$ " y $3 / 8$ " (12,7mm - 9,5mm); se introdujo en el tambor toda la muestra -esto es $5.000 \mathrm{~g}$ - y se la sometió al impacto de 11 esferas de acero, durante 500 giros, a razón de $31 \mathrm{rpm}$. Se procedió como indica la norma para determinar el coeficiente de desgaste, que dio $24 \%$ de pérdida. Nosotros tamizamos todo el material y dibujamos su granulometría, para compararla con la muestra original. En la figura se representó con línea de trazos negra, la gradación $\mathrm{B}$ que es $100 \%$ pasa tamiz $3 / 4$ "; $50 \%$ pasa tamiz $1 / 2 " y$

$0 \%$ pasa tamiz 3/8" y con trazos de color bordó lo que resultó de la degradación por acción del ensayo; puede observarse que lo que pasa por el tamiz $\mathrm{N}^{\circ} 12$ es $24 \%$-o sea es el coeficiente LA-B. 
E1 Indice de Degradación, lo obtuvimos con el siguiente cálculo:

$$
[(100-100)+(87,8-50)+(71,8-0)] / 3=36,5
$$

Según se definió anteriormente, el primer paréntesis corresponde a los valores del tamiz

de $3 / 4$ ", el segundo paréntesis a los valores de $1 / 2$ " y el tercero a los de $3 / 8$ " y se divide por tres porque ese es el número de tamices involucrados.

Repetimos el ensayo con otra partida de material -de la misma cantera, la misma fracción nominal- que llamamos granito 2 y volcamos los datos en una tabla Excel para poder graficarlos. Se obtuvieron pérdida por desgaste Los Angeles: 25,7\% e Indice de Degradación: 36,5.

La Dirección Nacional de Vialidad, pide -en su Pliego de Especificaciones- para el agregado grueso a utilizarse en concretos asfálticos densos, una resistencia al desgaste Los Angeles inferior a $25 \%$.
Continuando con nuestro estudio; si ahora presentamos todas las curvas en el mismo gráfico, podemos comparar mejor el comportamiento de ambas partidas, desde el punto de vista del desgaste por atricción, producido por el equipo Los Angeles.

La Figura 1 demuestra que si bien los coeficientes de desgaste están uno por debajo de 25 y el otro superando ese valor, la degradación que experimenta el material es igual en ambas partidas; las curvas se entrelazan y los valores son muy similares, con lo que estamos diciendo que el comportamiento de estos áridos a posteriori del ensayo Los Angeles no presentan singularidades que los distingan. Sin embargo algunas Especificaciones rechazarían el segundo material, porque quien ejerce el control de obra entendería que con ese valor superior, los áridos no son suficientemente duros como para resistir el proceso de fabricación de la mezcla asfáltica, la posterior compactación en obra con equipos pesados ni el tránsito.

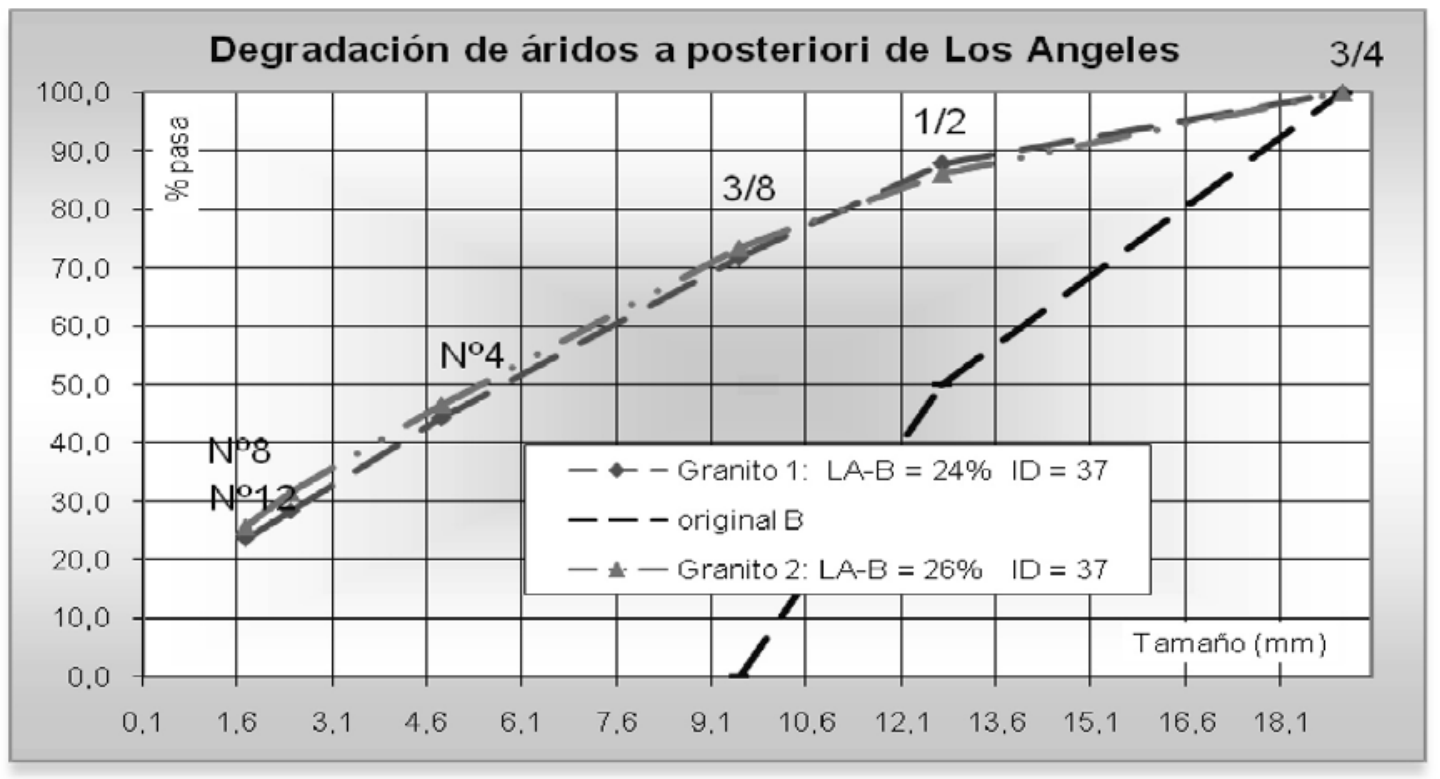

Figura 1 
Para establecer alguna relación entre el efecto de los impactos producidos por los ensayos de Fragmentación Dinámica y de desgaste por el método de Los Angeles, con los impactos que produce la compactación de laboratorio utilizando el equipo Marshall; se desagregaron probetas que habían sido compactadas con distintas energías de compactación. Para lograrlo se recurrió al ensayo VN-60-78 Determinación del Contenido de Asfalto utilizando una centrífuga con la misma energía; algunas sufrieron 10 golpes adicionales y otras 30 por cara.

Se calcularon los índices de degradación promediando la diferencia para los tamices de $12.7 \mathrm{~mm}(1 / 2 ")-9.5 \mathrm{~mm}(3 / 8 ")-4.8$ $\mathrm{mm}\left(\mathrm{N}^{\circ} 4\right)$ y $2.4 \mathrm{~mm}\left(\mathrm{~N}^{\circ} 8\right)$ y nos encontramos con valores muy inferiores a los determinados anteriormente. Esto prueba que la acción de los impactos sobre los áridos solos, es mucho más severa que cuando estos están componiendo la mezcla asfáltica.

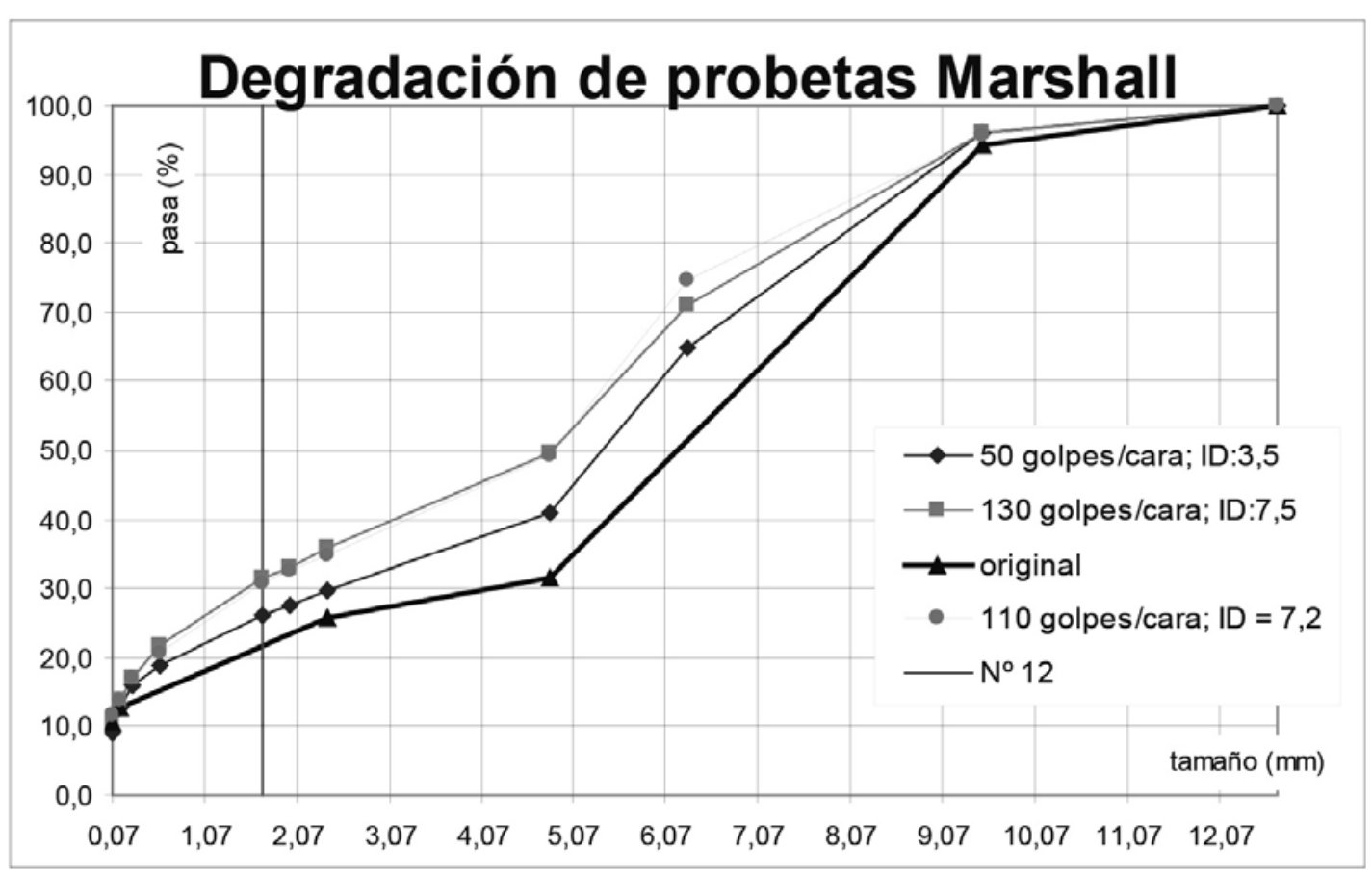

Figura 2

que en su interior contiene un plato, que alojará la muestra y un solvente. Finalizado el ensayo se determina el porcentaje de cemento asfáltico y se obtiene la mezcla de áridos desagregada y sin ligante.

La Figura 2 muestra las tres curvas de degradación y la granulometría de la mezcla original; las probetas fueron compactadas con 50 golpes por cara y recompactadas
A la misma conclusión habían arribado los ingenieros Alvarez y Añon Suárez cuando escribieron que... "El producto asfáltico que rodea las particulas cumple además de su función ligante, otra de mucha importancia, cual es la de actuar como amortiguador de los esfuerzos transmitidos por el tránsito, disminuyendo en consecuencia el efecto degradante... (REF 4) 
REFERENCIAS BIBLIOGRÁFICAS:

1 VIGENCIA, ALCANCE E INTERPRETACION DEL EXAMEN Y ENSAYOS DE AGREGADOS PETREOS PARA CONTROLES DE OBRA EN PAVIMENTOS ASFALTICOS de Saumench S. Octavo Simposio de la C.P.A. sobre Control de Calidad en Pavimentos Asfálticos. 1982

2 EL AGREGADO PETREO EN LAS ESPECIFICACINES PARA CONCRETO ASFALTICO EN CALIENTE por Villabona de Suárez N. Octavo Simposio de la C.P.A. sobre Control de Calidad en Pavimentos Asfálticos. 1982

3 LA DEGRADACION DE LOS MATERIALES GRANULARES EN RELACION CON SU DURABILIDAD EN SERVICIO por J. Lockhart y C. Marchetti. V Congreso Argentino de Vialidad y Tránsito. 1964

4 DESGASTE DE AGREGADOS PETREOS A UTILIZAR EN MEZCLAS ASFALTICAS. SU MEJOR CONOCIMIENTO por Alvarez M., Añón Suárez H. IX Congreso Argentino de Vialidad y Tránsito. 1981

5 COMPORTAMIENTO DE ARIDOS SOMETIDOS A DISTINTOS TIPOS DE IMPACTO por S. Alvarez, L. Romero, R. Montupil y P. Sbaizero. XXXVI Reunión del Asfalto. 2010

6 CRITERIOS PARA EL EMPLEO DE AGREGADOS PETREOS EN PAVIMENTOS ASFALTICOS por S. Saumench y J. Colombo. Segundo Congreso Latinoamericano del Asfalto. 1983 